\title{
Chloroquine, an autophagy inhibitor, potentiates the radiosensitivity of glioma initiating cells by inhibiting autophagy and activating apoptosis
}

Hongxing Ye ${ }^{\dagger} \mathbb{D}$, Mantao Chen ${ }^{\dagger}$, Fei Cao, Hongguang Huang, Renya Zhan ${ }^{*}$ and Xiujue Zheng*

\begin{abstract}
Background: Glioblastoma is refractory to conventional treatment, which is combined of surgery, chemotherapy and radiotherapy. Recent studies have shown that glioma initiating cells (GICs) contribute to tumorigenesis and radioresistance. Recently, other studies showed that the GICs use the autophagy as the major pathway to survive. Chloroquine, an anti-malarial chemical, is an autophagic inhibitor which blocks autophagosome fusion with lysosome and slows down lysosomal acidification. The aim of this study was to explore the mechanisms of chloroquine on the radiosensitivity of GICS.
\end{abstract}

Methods: Human glioblastoma cell lines U87 were investigated. MTT and clonogenic survival assay were used to evaluate the cell viability and survival from radiation. The formation of autophagosomes were evaluated by immunofluorescence. Annexin V-FITC/PI staining and flow cytometry were used to quantify the apoptotic cells. The expression levels of proteins were analyzed by Western blot. Cell cycle status was analyzed by checking DNA content after staining with PI. A comet assay was used to assess the DNA repair in the cells. Tumorsphere assay was used for evaluating GICs' renewal ability.

Results: Treatment of U87 GICs with chloroquine (10-80 nmol/L) alone inhibited the cell growth in a dosedependent manner. A dose of chloroquine $(20 \mathrm{nmol} / \mathrm{L})$ obviously enhanced the radiation sensitivity of U87 GICs., we found more punctate patterns of microtubule-associated protein LC3 immunoreactivity in radiation-treated U87 GICs, and the level of membrane-bound LC3-II was obviously enhanced. A combination of radiation and chloroquine obviously enhanced the U87 GlCs' apoptosis, as demonstrated by the enhanced levels of caspase-3, and reduced level of $\mathrm{BCl}-2$. In additon, combination of radiation and chloroquine cause G1/G0 cell cycle arrest. what's more, Chloroquine obviously weakened the repair of radiation-induced DNA damage as reflected by the tail length of the comet. Combination treatment of irradiation and chloroquine has synergistic effects on decreasing the GICs' tumorsphere number and diameter.

Conclusion: Chloroquine enhances the radiosensitivity of GICs in vitro, suggesting the feasibility of joint treatment with chloroquine with radiation for GBM.

Keywords: Glioma initiating cells, Radiosensitivity, Irradiation, Apoptosis, Autophagy, Chloroquine

\footnotetext{
* Correspondence: zxj8065@sina.com; zhanry1960@163.com

${ }^{\dagger}$ Equal contributors

Department of Neurosurgery, First Affiliated Hospital, School of Medicine,

Zhejiang University, No. 79 Qingchun Road, Hangzhou, Zhejiang, People's

Republic of China
} 


\section{Background}

Glioblastoma (GBM) is the most malignant and common primary neoplasm in central nervous system. Despite the advances in conventional treatments, comprised of surgical resection, radiotherapy and chemotherapy, the median duration of survival of GBM is 14.6 months after first diagnosis [1]. Recent studies report that a minority subset of the whole glioma population is glioma initiating cells (GICs), which led to tumorigenesis, because these GICs show enhanced self-renewal ability, multipotent differentiation that GICs can epitomize the original tumor in vivo [2]. GICs are considered "seed" cells and have strong radio-chemoresistance and tumorigenic potential $[3,4]$. Bao $\mathrm{S}$ et al. found primary tumor cells are less radioresistant than GICs, and GICs were responsible for tumor recurrence after radiotherapy [5]. Although surgery followed by radiation and chemotherapy could eradicate most part of glioma cells, they did not kill GICs. Thus, GICs are the novel cellular targets and their elimination can hinder cancer progression and recurrence.

Autophagy is also named type II programmed cell death pathway, which is different from the apoptotic type I death pathway [6]. Autophagy is a balance that weights between reconstruction, energy equilibrium, cell death and survival, correspondingly, with the internal or external stimulations accepted. Autophagy has different effects on tumor outcomes: it is essential for some forms of cancer cell death, but it can help cancer growth by assisting cancer cells fight hard cancer environment (e.g., malnutrition, shortage of oxygen) and combat radiotherapy and chemotherapy [7]. Yao found that ionizing radiation (IR) of human glioma cells led to increased autophagy [8]. Other studies showed that the induction of autophagy by radiotherapy result in the radioresistance of GICs [9]. Therefore, discovery of a novel combination treatment, such as radiotherapy or chemotherapy combines autophagy suppression may be a feasible and promising strategy.

Chloroquine is an anti-malaria drug, which has been used for over eighty years. Recent years, choloroquine, as an autophagy inhibitor, is drawing more and more attentions [10]. Chloroquine-treated tumor cells are not able to exploit autophagy as an substituting source of energy and will die [11].

Researchers found that chloroquine combined with chemo-radio-therapy, increased the duration of survival of glioblastoma patients [12, 13]. However, other researchers reported that the chloroquine treatment was found not to be effective for the medical treatment of malignant astrocytomas [14].

Therefore, the clinical effect of joint treatment with radiation and chloroquine on the radioresistance of malignant glioma and GICs remains uncertain. We investigate the potential radiosensitization effect and its probable mechanisms of chloroquine on GICs.

\section{Methods \\ Preparation of $\mathrm{CD} 133^{+}$U87 GICs, cell culture, and reagents}

The human glioma cell lines U87 were purchased from the Shanghai Institute of Biochemistry (Shanghai, China). To isolate human $\mathrm{CD}_{133^{+}} \mathrm{U} 87$ GICs, Glioma cell line U87 was cultured at $37{ }^{\circ} \mathrm{C}$ in the presence of $5 \% \mathrm{CO} 2$ in the medium containing $90 \%$ Dulbecco's modified Eagle's medium (DMEM) and $10 \%$ Fetal Calf Serum (FBS). After having digested with trypsin, resuspended, centrifuged, and purified by magnetic separation using anti-CD133 microbeads (Miltenyi Biotec) per the manufacturer's instructions, CD133 negative cells were also obtained at the same time and cultured in conditions appropriate for growth. The human CD133+ U87 GICs, were then cultured at $37{ }^{\circ} \mathrm{C}$ in the presence of $5 \%$ $\mathrm{CO} 2$ in the serum-free DMEM/F12 culture medium, supplemented with B27 (2\%), firoblast growth factor, N2 supplement, and epidermal growth factor. The medium was replaced every 3-5 days. We observed and counted the attachment and suspension of cells twice per day. Chloroquine was purchased from Sigma.

\section{Cell viability assay}

Cell viability was measured by MTT assays. Cells were seeded in 96-well microplates $\left(1 \times 10^{5}\right.$ cells or $1 \times 10^{4}$ cells/well). After incubation at $37{ }^{\circ} \mathrm{C}$ in the presence of $5 \% \mathrm{CO} 2$ in constant temperature and humidity incubator for 3-5 days, the tumor cells were treated using different doses of chloroquine or radiotherapy alone or in combination. We set up a control group and a zero adjustment group. At specified time points, 20ul of MTT solution $(5 \mathrm{mg} / \mathrm{mL}$ ) was added $4 \mathrm{~h}$ before the end of the incubation duration, the reaction was stopped by the addition of $150 \mu \mathrm{L}$ dimethylsulfoxide (DMSO). The optical density (OD) or absorbance was read at $490 \mathrm{~nm}$.

\section{X-rays}

Radiation was performed using a 6-MV X-rays from a linear accelerator (PRIMUS, DE, Siemens A\&D LD, Nelson Avenue Concord, USA).

\section{Clonogenic assay}

Cells were seeded in six-well plates $(2 \times 102$ cells/well). After $12 \mathrm{~h}$ incubation, cells were treated and irradiated. After two weeks, the colonies were fixed with methanol for $15 \mathrm{~min}$ and stained with $0.5 \%$ crystal violet. Colonies with at least 50 cells were counted. 


\section{Immunofluorescence}

The U87 GICs were plated onto coverslips and treated with $20 \mu \mathrm{M} / \mathrm{L}$ concentration of chloroquine and 6 Gy dose of radiation for $24 \mathrm{~h}$. After fixation with $4 \%$ paraformaldehyde, tumor cells were incubated with blocking buffer (0.1 \% Triton X-100, 2 \% horse serum) for 30 min at $37{ }^{\circ} \mathrm{C}$, and with the rabbit anti-human light chain 3 antibody (LC3) (1:200, Abcam) at $4{ }^{\circ} \mathrm{C}$ for overnight. After wash, a secondary antibody (1:200) conjugated to Alexa 488 (Invitrogen) was added and incubated for $1 \mathrm{~h}$ at room temperature. Fluorescent cells were examined with a confocal microscope to appraise the formation of autophagosomes.

\section{Western blot analysis}

The cells were lysed with a lysis buffer (Beyotime, Haimen, China), and centrifuged at $12,000 \times \mathrm{g}$ for $20 \mathrm{~min}$. The total protein concentration was determined using the a BCA protein assay kit (Pierce). Samples were resolved in SDS-PAGE, transferred to $0.45 \mu \mathrm{m}$ nitrocellulose transfer membranes and analyzed separately. After blocking with $5 \%$ skim milk at room temperature for $60 \mathrm{~min}$, the blots were survey with primary antibodies against mouse anti-Bcl-2 (1:500; Abcam), rabbit anti-LC3 (1:1000; Abcam), mouse anti-GAPDH (1:1000; Cell Signal), and rabbit anti-active caspase-3 (1:1000; Abcam), at $4{ }^{\circ} \mathrm{C}$ for overnight. We washed the membranes three times with TBST buffer $(20 \mathrm{mmol} / \mathrm{L}$ Tris-buffered saline and $0.1 \%$ Tween 20) for $1 \mathrm{~h}$. And we used peroxidase conjugated anti-mouse-IgG/anti rabbit-IgG as secondary antibodies. We did Chemiluminescence with Amersham ECL plus Western blotting detection system (GE healthcare). After washing with the TBST buffer, the membranes were measured with the Odyssey Infrared Imaging System (LI-COR).

\section{Flow cytometric apoptosis assay}

The cells in the different treatment groups were measured using an Annexin V FITC Kit (Sigma, St Louis, $\mathrm{MO}$ ). Earlier stages apoptotic (annexin V+) (PI-) cells were identified by flow cytometry on a BD FACS flow cytometer (San Diego, CA).

\section{Cell cycle analysis}

$5 \times 10^{5}$ cells per sample were collected after centrifugation at 1000 r.p.m for $5 \mathrm{~min}$. The cells re-suspended with $0.5 \mathrm{ml} \mathrm{PBS}$ and fixed with ice-cold $70 \%$ ethanol overnight at $4{ }^{\circ} \mathrm{C}$. Fixed cells were washed with PBS and stained with propidium at room temperature for $1 \mathrm{~h}$. The cells were subsequently measured by FACScan (Becton-Dickinson, San Diego, CA, USA).

\section{DNA damage}

A comet assay quantitatively assesses DNA repair in U87 GICs. The detailed procedure of the comet assay performed in this experiment refers to the report of Wang et al. [15]. The comet assay metric for DNA damage induced by the treatment was tail DNA (\%). We analyzed images from 50 cells ( 25 from each replicate slide).

\section{Neurosphere assay}

We trypsinized the U87 GICs and seeded equal numbers of GICs in 48 well plates, and treated as indicated. Five days after treatment, we counted total neurospheres numbers and photographed.

\section{Statistical analysis}

The experimental data is showed as the mean $\pm \mathrm{SD}$. All experiments were performed three times. Unpaired Student's $t$ test was performed to analyses the significance between experimental groups. Statistically significant $P$ values are indicated in the figures with asterisks: ${ }^{* *}, P<$ $0.01 ;{ }^{*}, P<0.05$. We used GraphPad software (Inc.; version 5.02) for all statistical analyses.

\section{Results}

Irradiation and chloroquine had synergetic effect on U87 GICs

The inhibitory effect of irradiation or chloroquine on cell viability in GICs was evaluated after $72 \mathrm{~h}$ treatment. As shown in Fig. 1a, a dose-dependent inhibitory action on cell growing was assessed with irradiation or chloroquine alone. As shown in Fig. 1b, we seeded cells onto 96-well plates, and quantified the number of cells at indicated time points by MTT assay. Irradition and chloroquine had synergistic inhibitory effect on U87 GICs. Furthermore, We found that clonogenicity of U87 GICs treated with radiation or radiation plus chloroquine were obviously decreased in an radiation-dose dependent manner (Fig. 1c). And the clonogenicity of the combined group was significantly decreased, compared with radiation treatment alone, suggesting chloroquine treatment obviously enhanced radiation sensitivity in GICs. As shown in Fig. 1d, there was obviously enhanced in the number of cells in the G0/G1 phase in the combined group $(88.91 \% \pm 5.13 \%)$ compared with the control group $(49.75 \% \pm 2.58 \%)$. This increase suggested that combination treatment of irradition and chloroquine significantly promoted a cell-cycle arrest in G0/G1 phase.

\section{IR with chloroquine synergistically induced apoptosis}

To explore whether the synergistic cytotoxicity was related to apoptosis, U87 GICs were processed with Xray $(6 \mathrm{~Gy})$ or chloroquine $(20 \mu \mathrm{M})$ alone or combination of both for $24 \mathrm{~h}$, and the induction of apoptosis was assessed by AnnexinV-FITC/PI double staining. As 

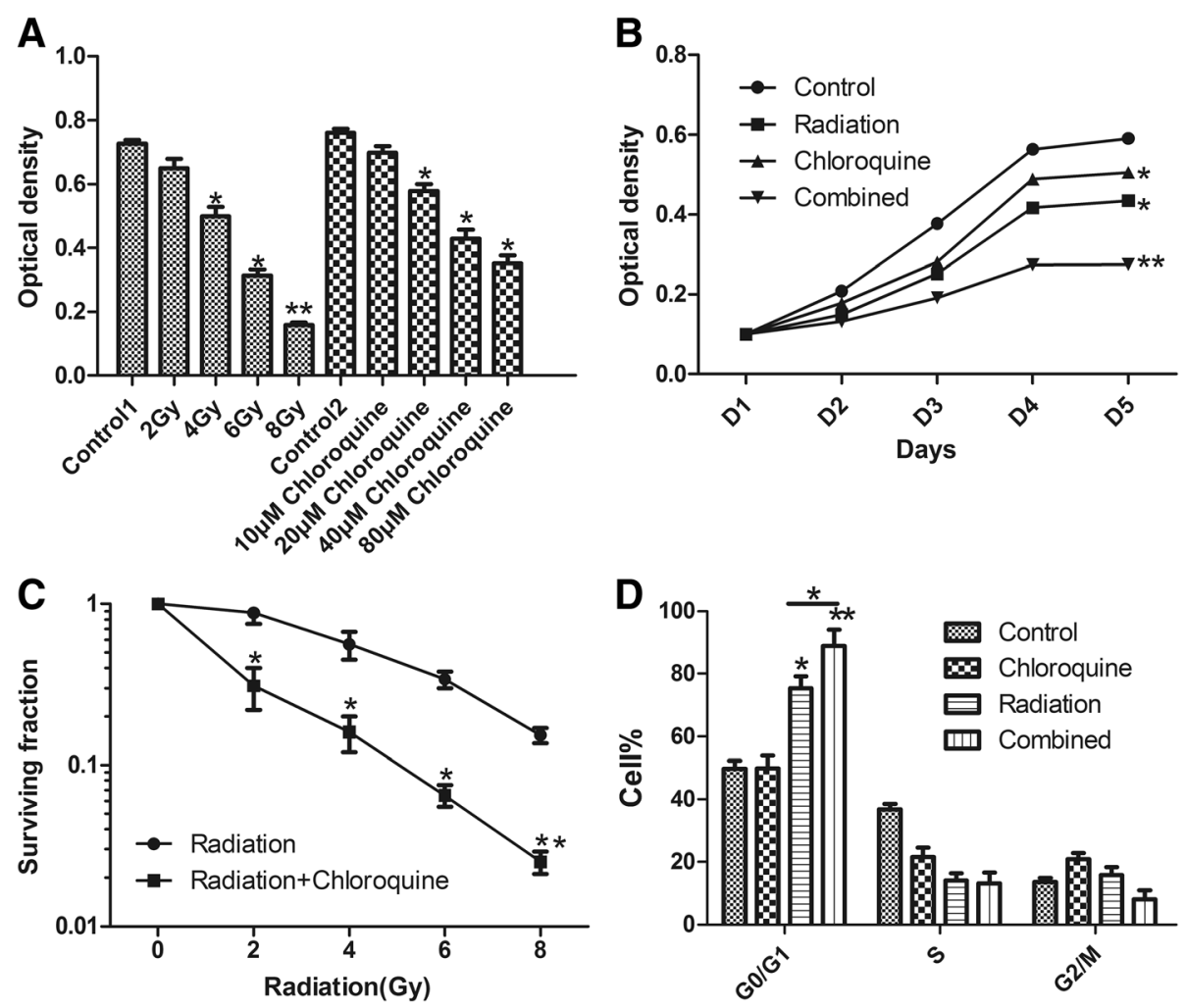

Fig. 1 Effects of X-ray and chloroquine alone or combination on the viability of U87 GICs. a Human glioma cell line U87 GICs were plated in 96 -well plates $(1 \times 105 /$ well), treated with various dose of X-ray or different concentration of chloroquine alone for $72 \mathrm{~h}$. Cell viability was examined by MTT assay. It demonstrated that X-ray and chloroquine suppressed cell viability in dose-dependent manner. Each bar represents mean \pm SD of triplicate determinations; results shown are representative of three identical experiments. $\mathbf{b}$ U87 GIC were plated in 96-well plates $(5 \times 104 /$ well), and treated with 6Gy X-ray or $20 \mu \mathrm{M}$ chloroquine alone or combination. At indicated time points a MTT assay was performed to assess the cell number, as measured by absorbance(OD). c Clonogenic survival 14 days after treatment with radiation alone(0Gy to $8 \mathrm{~Gy})$, radiation plus chloroquine $(20 \mu \mathrm{M}) .\left({ }^{*} p<0.05,{ }^{* *} p<0.05, n=3\right)$. d Quantification of cell cycle distribution of U87 GIC, using flow cytometry and PI, staining $48 \mathrm{~h}$ after treatment. Radiation combined chloroquine significantly increased number in G0/G1 phase compared to radiotherapy alone group $\left({ }^{*} p<0.05,{ }^{* *} p<0.05, n=3\right)$

shown in Fig. 2a-b, The percentage of early apoptotic tumor cells(AnnexinV-FITC positive, PI negative) in the combined treatment(35.06 \% $\pm 6.98 \%)$ was significantly higher than that with radiation $(16.73 \% \pm 4.52 \%)$ or chloroquine $(6.94 \% \pm 1.21 \%)$ alone.

To investigate the expression of proteins associated with apoptosis in U87 GICs, we cultured cells with 6Gy radiation or $20 \mu \mathrm{M}$ chloroquine alone, or the two in combination for $24 \mathrm{~h}$. We The analyzed the expression levels of apoptosis associated proteins from each group by Western blotting. Combined treatment obviously increased the expression of Caspase-3(Fig. 2c), and decreased the expression of the antiapoptotic $\mathrm{Bcl}-2$.

\section{Chloroquine inhibits autophagy induced by IR}

LC3-II could be seen in punctate structure mainly representing autophagosomes. The location of LC3 was assessed by indirect immunofluorescence microscopy. By fluorescence microscopy assay(Fig. 3a-b), the numbers of GICs with $\mathrm{LC} 3+$ puncta in the radiation alone group (13\%) was obviously more than that in chloroquine alone $(4 \%)$ or control ( $2 \%)$ group, and in combined group (6\%), chloroquine significantly inhibited the autophagy induced by IR. Moreover, to test whether different treatments induced different autophagy in U87 GICs, we assessed the protein expression of LC3-II, a mammalian homologue of ATG8 located in autophagosomes. U87 GICs were treated with 6Gy IR or $20 \mu \mathrm{M}$ chloroquine alone, or the combination of the two for $48 \mathrm{~h}$, and the ratio of the LC3-II/LC3-I were determined by western blot. As shown in Fig. 3c-d, LC3-II level was obviously enhanced in radiation group, and it was significantly decreased by the combined treatment.

\section{Chloroquine weakens the repair of radiation-induced DNA damage in GICs}

As one of pivotal mechanism involved in radioresistance is DNA repair, the effects of chloroquine on radiationinduced celluar genomic DNA damage were examined by the alkaline comet assay. In our study, we assessed 


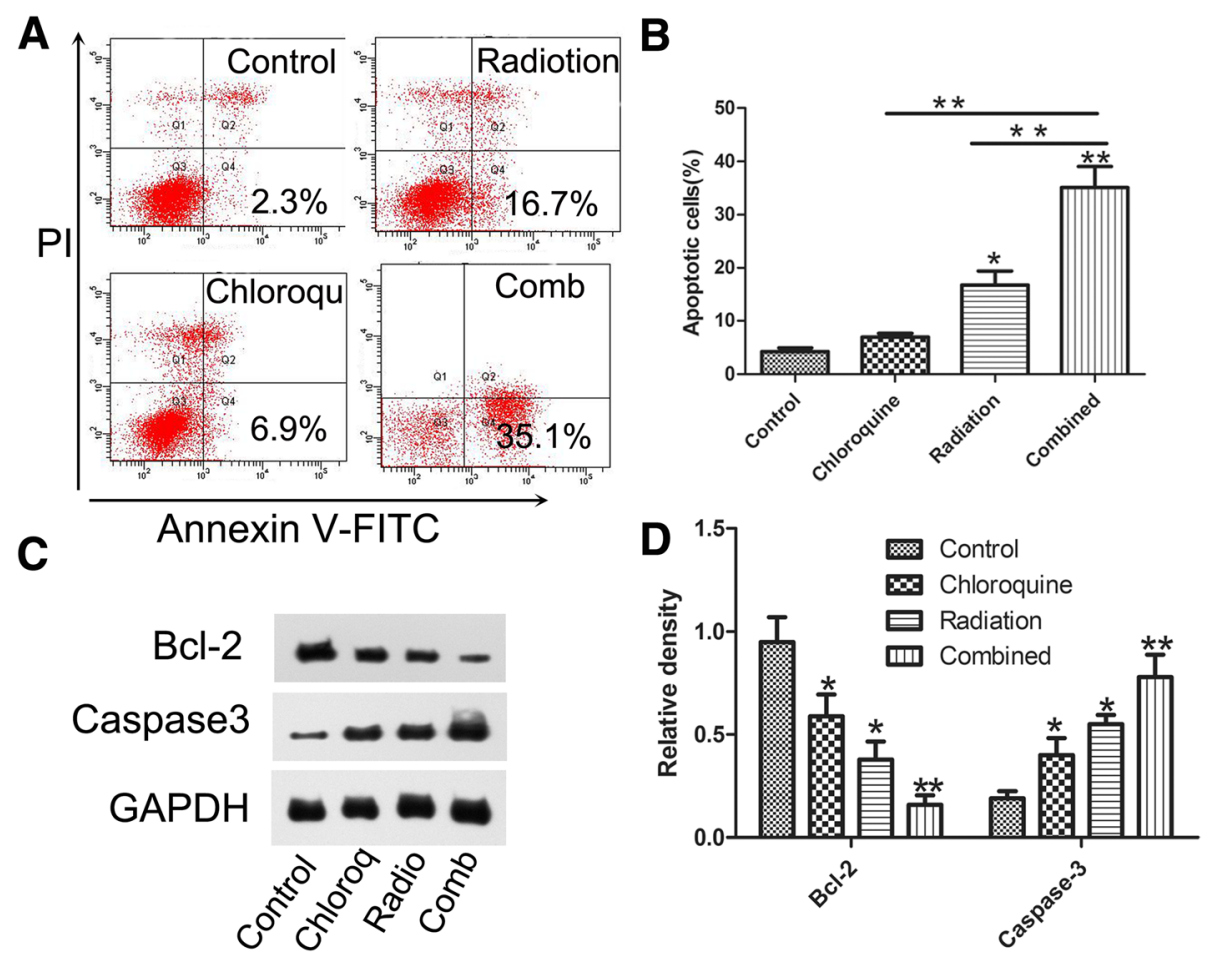

Fig. 2 Combination treatment of irradiation and chloroquine obviously promoted apoptosis in U87 GIC. a U87 GIC were treated with X-ray(6Gy) alone and chloroquine $(20 \mu \mathrm{M})$ alone or in combination for $24 \mathrm{~h}$, and the promotion of apoptosis was measured using AnnexinV-FITC/PI double staining. $\mathbf{b}$ Quantitative analysis of apoptotic cells. Data are demonstrated as the mean $\pm \mathrm{SD},{ }^{*}, p<0.05,{ }^{* *} p<0.01, n=3$. $\mathbf{c}$ Apoptosis -associated proteins were investigated by Western blotting. $\mathbf{d}$ Relative density of $\mathrm{BCl}-2$ and Cleaved caspase- 3 versus GAPDH in each sample measured by densitometry of the blots. Densitometric analysis of the immunoblot is expressed as a percentage of control. Data are presented as the mean \pm $\mathrm{SD},{ }^{*}, p<0.05$ versus control, ** $p<0.01$, versus control, $n=3$

genomic DNA damage in GICs at $24 \mathrm{~h}$ after treatment. We determined DNA damage by assessing the tail length of the comet with a microscope. DNA damage was more severe in the combined group than in IR or chloroquine alone group at $24 \mathrm{~h}$ after treatment. The data is demonstrated as the mean $\pm \mathrm{SD}$ from more than 50 cells. Each group was analyzed in 3 times (Fig. $4 \mathrm{~b}$ ). Then, chloroquine treatment was used to prevent the repair of radiation-induced DNA damage.

\section{Co-treatment inhibits self -renewal effect on U87 GICs}

Sphere forming assay has been widely applied to monitor the self-renewal ability of GICs. We observed the combined treatment had strong inhibitory effects in tumorsphere forming assays conducted as a stem cell surrogate assay to measure the effect on clonogenic cells. In this study, the combination of chloroquine $(20 \mu \mathrm{M})$ and a 6 Gy ionizing radiation turned out to be very potent, probably because of the strong cytostatic effect on GICs. As shown in Fig. 5, the number of the tumorsphere in the combined treatment was significantly smaller than that in chloroquine or IR alone group. The diameter of tumorsphere $(47 \pm 8 \mu \mathrm{m})$ in the combination was also smaller than that in chloroquine $(116 \pm 9 \mu \mathrm{m})$ or IR $(87 \pm 11 \mu \mathrm{m})$ alone group.

\section{Discussion}

In the present study, we explored the radiosensitizing action of an autophagy blocker chloroquine in GICs, and aimed to further understand the molecular mechanisms of its effect. We found that chloroquine or radiation alone inhibited U87 GICs growth in a dosedependent manner. The combined inhibitory effect of chloroquine and radiation on the viability of human GICs was stronger than that of chloroquine or radiation alone, in a synergetic way (Fig. 1a-c). The response of GICs to radiation was associated with autophagy and the late autophagy inhibitor chloroquine in combination with radiation caused G0/G1 phase arrest, promoted GICs' apoptosis and impaired the repair of radiationinduced DNA damage in GICs, and decreased the GICs' tumorsphere numbers and diameters.

Recent researches demonstrated that cancer stem cells could exploit autophagy to survive and accelerate their renewal [16, 17]. GICs, as the most radioresistant cell subset and autophagy targeting, may be helpful to cure the disease $[18,19]$. Our data indicates that irradiation 

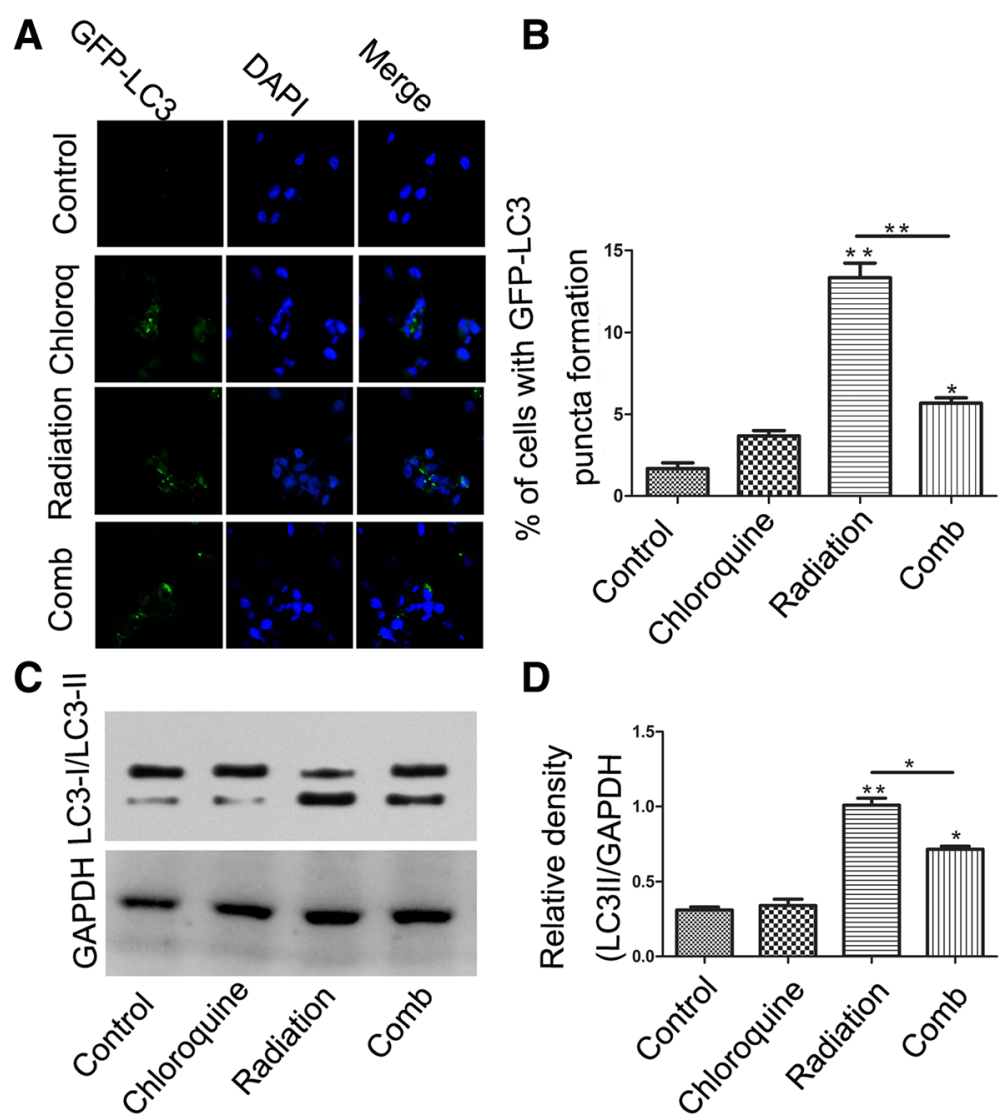

Fig. 3 Irradiation obviously promoted autophagy and obviously enhanced autophagy associated proteins expression in U87 GICS, and chloroquine can significantly inhibit the autophagy process which induced by radiation. a Representative images $(\times 200)$ of the indicated regions of U87 GICS, which analyzed for LC3 expression by immunofluorescence analysis. b Quantitative analysis of the number of cells with punctuate GFP-LC3. c Authophagy-associated protein LC3 level in U87 GICs were examined by Western blotting. d Quantification of LC3 protein expression in U87 GICS treated by indicated treatments after normalization with GAPDH levels. Mean \pm SD. $n=3 .\left({ }^{*}, p<0.05 ;{ }^{* *} p<0.01\right)$

of U87 GICs results in enhanced autophagy. Chloroquine in combination with radiation inhibited the autophagy induced by radiation and strongly promoted GICs apoptosis. Apoptosis involved many diseases, especially malignant tumors. There are two main apoptotic pathways: the extrinsic or death receptor pathway and intrinsic or mitochondrial pathways [20]. Study finds that radiation is a stimulus that initiate the intrinsic pathway. The control and regulation of intrinsic pathway is through members of Bcl-2 family of proteins [21].
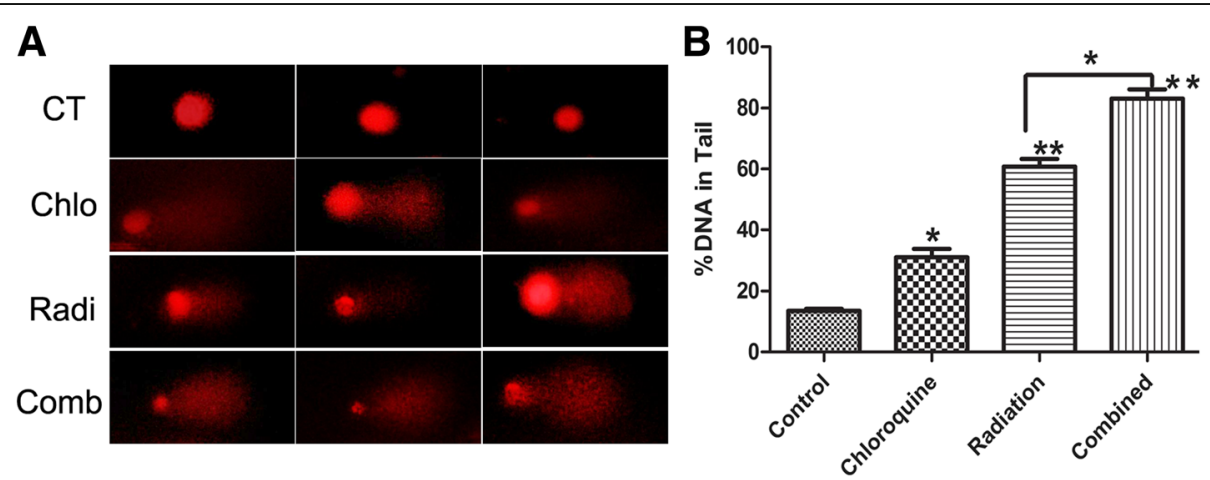

Fig. 4 Chloroquine weakens the repair of IR-induced genomic DNA damage in GICs. a GICs were treated radiation( $6 \mathrm{~Gy})$ and chloroquine(20 $\mu M$ ) and harvested at $24 \mathrm{~h}$ after radiation. The alkaline comet assay was used to measure treatment-induced DNA damage. Representative image of U $87 \mathrm{GICS}$ at $24 \mathrm{~h}$ after different treatments are demonstrated ( $800 \times$ magnification). b The quantification of the percentage of cells with comet tails at $24 \mathrm{~h}$ after treatment 

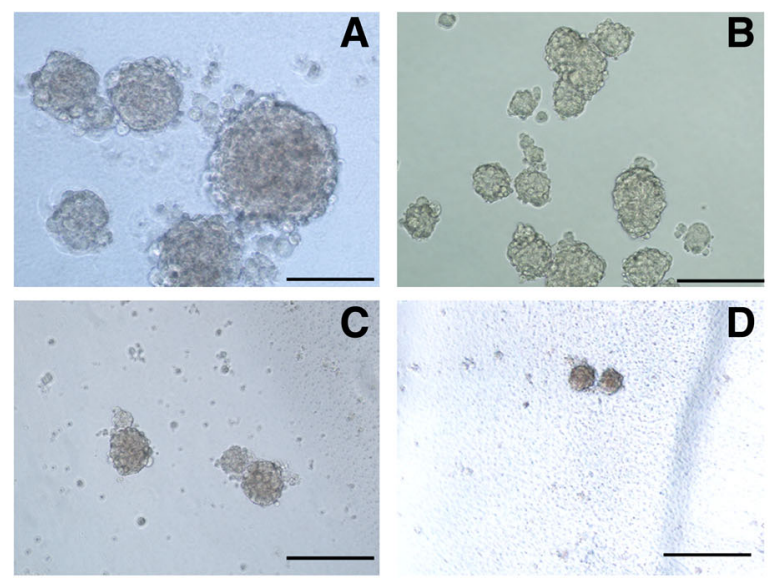

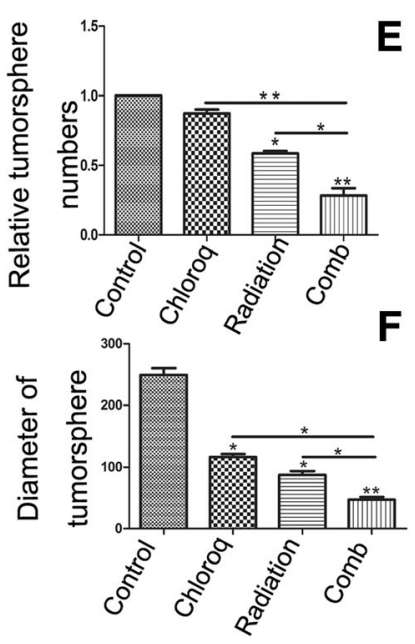

$\mathbf{E}$

$\mathbf{F}$

Fig. 5 Combination treatment of irradiation and chloroquine have synergistically effects on decreasing the GICs' tumorsphere numbers and diameters. a-d $\mathrm{U} 87 \mathrm{GICs}$ were treated as described before, then seeded in serum-free medium to generate tumorspheres,5 days after treatment, we counted and photographed total tumorspheres (a control group, $\mathbf{b}$ chloroquine group, $\mathbf{c}$ radiation group, $\mathbf{d}$ conbination group). e Quantitative analysis of the relative tumorsphere numbers treated by indicated treatments. $\mathbf{f}$ Quantitative analysis of the diameter of the tumorspheres treated by indicated treatments. $\left({ }^{*}, p<0.05,{ }^{* *} p<0.01\right)$

Here, we found that the combination of chloroquine and radiation reduced anti-apoptotic $\mathrm{Bcl}-2$, up-regulated caspase-3, and enhanced the fraction of Annexin VFITC positive and PI negative cells to $35.1 \%$. However, about 16.7 and $6.9 \%$ respectively were measured with treatment of radiation or chloroquine alone (Fig. 2). These results may suggest that the combined inhibitory effect cause apoptosis at least in part by the intrinsic pathway. These results demonstrate that chloroquine plays a synergetic role in radiation-induced viability inhibition and apoptosis in U87 MG GICs. The result may be helpful to explaining the results of a clinical trial that chloroquine, added to a comprehensive therapeutic protocol (operation plus radiotherapy and chemotherapy) for glioblastoma, significantly prolonged the median overall survival compared with control groups [22]. Other study on the combining of radiation with chloroquine for the management of recurrent glioblastoma validated the feasibility of the regimen and the authors reported encouraging therapy outcomes [23].

Growing evidences suggest that chloroquine is a strong anticancer drug in managing several cancers, such as leukemia and hepatocarcinoma [24, 25]. Yuan et al. showed that suppression of ATG5 by siRNA or suppression of autophagy using 3-methylademine enhanced the radiosensitisation action of gliomas after STAT3 suppression [26]. Other research demonstrated that high expression levels of early growth response 1, which induces autophagy, is produced by the resistant clones of GICs [27]. In addition, mitochondrial isoenzyme of NADP + -dependent isocitrate dehydrogenase siRNAtransfected A172 glioma cells were sensitised after suppression of autophagy [28]. Firat, E et al. also demonstrated that induced-autophagy effects of PI3K/Akt pathway inhibitors obviously prevent cell death induction in $\gamma$-irradiated GICs, however, chloroquine significantly promotes $\gamma$ IR-induced cell death in highly radioresistant GICs [29]. Our study should be of high clinical significance, one reason is all data presented are focused on GICs, a population thought to be pivotal, because for cancer progression and therapy resistance that must be uproot in order to obtain long-term recurrence-free survival, another reason is that a clinically applicable late autophagy inhibitor was used. However, the present study has two limitations. First, our data presented here have been obtained from cell lines, not from patients's tumor-derived stem-like cells. Second, the further experimentation with animal models and clinical trials were not investigated in this study.

\section{Conclusion}

We have shown that inhibition of autophagy in combination with radiation is a promising therapeutic strategy for targeting GICs. The radiosensitization efficiency of chloroquine is obtained by inhibiting autophagy, weakening the capacity for DNA repair in the early stage and promoting cell-cycle arrest in addition to apoptotic responses.

\section{Abbreviations}

DMSO: Dimethylsulfoxide; EDTA: Na2-ethylenediaminetetraacetic acid; GBM: Glioblastoma; GICs: Glioma initiating cells; IR: lonizing radiation; LC3: Light chain 3; OD: Optical density; PBS: Phosphate-buffered saline; PI: Propidium iodide

Acknowledgements

Not applicable. 


\section{Funding}

This work was supported by grants of Zhejiang provincial Science and technology plan (No.2013C33248), Zhejiang Provincial Traditional Chinese Medicine Science and Technology Plan (No. 2016ZA122). Zhejiang Provincial Medical and Health Science and Technology Plan (No.2016KYA085).

\section{Availability of data and materials}

The dataset supporting the conclusions of this article is available.

\section{Authors' contributions}

$X J Z, R Y Z$ and $H X Y$ developed the idea and designed the research. HXY, and MTC wrote the manuscript, selected which studies to include and extracted the data from the studies, interpreted the analysis and drafted the final review. FC and $\mathrm{HGH}$ obtained copies of the studies and revised the writing. All the authors read and approved the final manuscript.

\section{Competing interests}

The authors declare that they have no competing interests.

\section{Consent for publication}

Not applicable.

\section{Ethics approval and consent to participate}

Not applicable.

Received: 22 June 2016 Accepted: 12 September 2016

Published online: 20 September 2016

\section{References}

1. Stupp R, Mason WP, van den Bent MJ, Weller M, Fisher B, Taphoorn MJ, Belanger K, Brandes AA, Marosi C, Bogdahn U, et al. Radiotherapy plus concomitant and adjuvant temozolomide for glioblastoma. N Engl J Med. 2005;352:987-96.

2. Kim SH, Ezhilarasan R, Phillips E, Gallego-Perez D, Sparks A, Taylor D, Ladner K, Furuta T, Sabit H, Chhipa R, et al. Serine/threonine kinase MLK4 determines mesenchymal identity in glioma stem cells in an NF-kappa Bdependent manner. Cancer Cell. 2016;29(2):201-13.

3. Valent $\mathrm{P}$, Bonnet D, Wohrer S, Andreeff M, Copland M, Chomienne C, Eaves C. Heterogeneity of neoplastic stem cells: theoretical, functional, and clinical implications. Cancer Res. 2013.

4. Brown CE, Starr R, Aguilar B, Shami AF, Martinez C, D'Apuzzo M, Barish ME, Forman SJ, Jensen MC. Stem-like tumor-initiating cells isolated from IL13Ralpha2 expressing gliomas are targeted and killed by IL13-zetakineredirected T cells. Clin Cancer Res. 2012;18(8):2199-209.

5. Bao S, Wu Q, McLendon RE, Hao Y, Shi Q, Hjelmeland AB, Dewhirst MW, Bigner DD, Rich JN. Glioma stem cells promote radioresistance by preferential activation of the DNA damage response. Nature. 2006;444(7120):756-60.

6. Choi AM, Ryter SW, Levine B. Autophagy in human health and disease. N Engl J Med. 2013;368(19):1845-6.

7. Zois CE, Koukourakis MI. Radiation-induced autophagy in normal and cancer cells: towards novel cytoprotection and radio-sensitization policies? Autophagy. 2009;5(4):442-50.

8. Yao KC, Komata T, Kondo Y, Kanzawa T, Kondo S, Germano IM. Molecular response of human glioblastoma multiforme cells to ionizing radiation: cell cycle arrest, modulation of the expression of cyclin-dependent kinase inhibitors, and autophagy. J Neurosurg. 2003;98(2):378-84.

9. Koukourakis MI, Mitrakas AG, Giatromanolaki A. Therapeutic interactions of autophagy with radiation and temozolomide in glioblastoma: evidence and issues to resolve. $\mathrm{Br} J$ Cancer. 2016;114(5):485-96.

10. Pascolo $\mathrm{S}$. Time to use a dose of Chloroquine as an adjuvant to anti-cancer chemotherapies. Eur J Pharmacol. 2016;771:139-44.

11. Chen TY, Syu JS, Lin TC, Cheng HL, Lu FL, Wang CY. Chloroquine alleviates etoposide-induced centrosome amplification by inhibiting CDK2 in adrenocortical tumor cells. Oncogenesis. 2015;4:e180.

12. Rosenfeld MR, Ye X, Supko JG, Desideri S, Grossman SA, Brem S, Mikkelson $T$, Wang $D$, Chang $Y C, H u$ J, et al. A phase I/II trial of hydroxychloroquine in conjunction with radiation therapy and concurrent and adjuvant temozolomide in patients with newly diagnosed glioblastoma multiforme. Autophagy. 2014;10(8):1359-68.
13. Briceno E, Calderon A, Sotelo J. Institutional experience with chloroquine as an adjuvant to the therapy for glioblastoma multiforme. Surg Neurol. 2007;67(4):388-91.

14. Bulut T, Ekici MA, Tucer B, Basarslan SK, Kamasak K, Kurtsoy A. The effect of chloroquine treatment in malignant astrocytomas on prognosis. Turk J Med Sci. 2013;43(5):782-9.

15. Wang WJ, Long LM, Yang N, Zhang QQ, Ji WJ, Zhao JH, Qin ZH, Wang Z, Chen G, Liang ZQ. NVP-BEZ235, a novel dual PI3K/mTOR inhibitor, enhances the radiosensitivity of human glioma stem cells in vitro. Acta Pharmacol Sin. 2013;34(5):681-90.

16. Gong C, Bauvy C, Tonelli G, Yue W, Delomenie C, Nicolas V, Zhu Y, Domergue V, Marin-Esteban V, Tharinger $\mathrm{H}$, et al. Beclin 1 and autophagy are required for the tumorigenicity of breast cancer stem-like/progenitor cells. Oncogene. 2013;32(18):2261-72. 2272e 2261-2211.

17. Berardi DE, Flumian C, Rodriguez CE, Bessone MID, Cirigliano SM, Joffe EDBD, Fiszman GL, Urtreger AJ, Todaro LB. PKC delta inhibition impairs mammary cancer proliferative capacity but selects cancer stem cells, involving autophagy. J Cell Biochem. 2016;117(3):730-40.

18. Yu VY, Nguyen D, Pajonk F, Kupelian P, Kaprealian T, Selch M, Low DA, Sheng K. Incorporating cancer stem cells in radiation therapy treatment response modeling and the implication in glioblastoma multiforme treatment resistance. Int J Radiat Oncol Biol Phys. 2015;91(4):866-75.

19. Shen Y, Chen H, Zhang J, Chen Y, Wang M, Ma J, Hong L, Liu N, Fan Q, Lu $X$, et al. Increased notch signaling enhances radioresistance of malignant stromal cells induced by glioma stem/progenitor cells. PLoS One. 2015; 10(11):e0142594.

20. Elmore S. Apoptosis: a review of programmed cell death. Toxicol Pathol. 2007;35(4):495-516.

21. Cory S, Adams JM. The BCL2 family: regulators of the cellular life-or-death switch. Nat Rev Cancer. 2002;2(9):647-56.

22. Sotelo J, Briceno E, Lopez-Gonzalez MA. Adding chloroquine to conventional treatment for glioblastoma multiforme: a randomized, doubleblind, placebo-controlled trial. Ann Intern Med. 2006;144(5):337-43.

23. Bilger A, Bittner Ml, Grosu AL, Wiedenmann N, Meyer PT, Firat $E_{1}$ Niedermann G, Weber WA, Milanovic D. FET-PET-based reirradiation and chloroquine in patients with recurrent glioblastoma. Strahlenther Onkol. 2014;190(10):957-61.

24. Chen P, Hu T, Liang YP, Jiang YN, Pan YF, Li CJ, Zhang P, Wei DP, Li P, Jeong $L S$, et al. Synergistic inhibition of autophagy and neddylation pathways as a novel therapeutic approach for targeting liver cancer. Oncotarget. 2015;6(11):9002-17.

25. Sehgal AR, Konig H, Johnson DE, Tang D, Amaravadi RK, Boyiadzis M, Lotze MT. You eat what you are: autophagy inhibition as a therapeutic strategy in leukemia. Leukemia. 2015;29(3):517-25.

26. Yuan XP, Du J, Hua S, Zhang HW, Gu C, Wang J, Yang L, Huang JF, Yu $J H$, Liu FJ. Suppression of autophagy augments the radiosensitizing effects of STAT3 inhibition on human glioma cells. Exp Cell Res. 2015;330(2):267-76.

27. Ye F, Zhang YB, Liu Y, Yamada K, Tso JL, Menjivar JC, Tian JY, Yong WH, Schaue D, Mischel PS, et al. Protective properties of radiochemoresistant glioblastoma stem cell clones are associated with metabolic adaptation to reduced glucose dependence. PLoS One. 2013;8(11):e80397.

28. Kim H, Bernard M, Flickinger J, Epperly MW, Wang H, Dixon TM, Shields D, Houghton F, Greenberger JS. The autophagy inducing drug carbamazepine is a radiation protector and mitigator. Cancer Res. 2011;71.

29. Firat E, Weyerbrock A, Gaedicke S, Grosu AL, Niedermann G. Chloroquine or chloroquine-PI3K/Akt pathway inhibitor combinations strongly promote gamma-irradiation-induced cell death in primary stem-like glioma cells. PLoS One. 2012:7(10):e47357. 